\title{
0 Lugar do Interculturalismo nas Políticas Imigratórias em Portugal e Espanha
}

\author{
Marcelo Ennes ${ }^{*}$ \\ Natalia Ramos ${ }^{* *}$ \\ Belén Suaréz $z^{* *}$
}

\section{Resumo}

A questão central deste artigo refere-se ao lugar do interculturalismo nas políticas de integração e gestão da diversidade produzida pelos imigrantes em Portugal e na Espanha nos primeiros anos do século XXI. Nosso objetivo principal foi conhecer como o interculturalismo, em sua polissemia, ganhou materialidade em avanços e recuos de normas e práticas desenvolvidas por órgãos governamentais visando a gestão da diversidade. Procuramos também conhecer a perspectiva de outros atores sociais, como representantes de associações ligadas ao tema da imigração. A pesquisa que deu origem ao artigo foi desenvolvida com base em pesquisa bibliográfica e documental, entrevistas qualitativas com base em roteiro pré-estruturado e observação direta. Os dados e os argumentos apresentados neste artigo permitem sustentar que se não é a solução definitiva para os problemas de racismos e xenofobia contra imigrantes, o interculturalismo tem sido um avanço no que diz respeito às políticas de imigração

\footnotetext{
* Professor Associado da Universidade Federal de Sergipe (UFS). Programa de Pós-graduação em Sociologia (PPGS/UFS). Grupo de Estudos e Pesquisa "Processos Identitários e Poder" (GEPPIP). E-mail: prof.marcelo.ennes@gmail.com.

** Professora Associada da Universidade Aberta, Lisboa, Portugal e Investigadora Coordenadora no Centro de Estudos das Migrações e das Relações Interculturais - CEMRI/ UAb, FCT. E-mail: Maria.Ramos@uab.pt.

*** Professora da Faculdade de Sociologia da Universidade da Corunha, Galicia, Espanha. E-mail: belen.fernandez.suarez@udc.es
} 
e integração do imigrante quando comparada, por exemplo, às políticas baseadas na ideia de assimilação.

Palavras-chave: Políticas imigratórias, interculturalismo, imigração, Portugal, Espanha.

\section{The Importance of Interculturalism in the Immigrations Policies in Portugal and Spain}

\section{Abstract:}

The central questions this article refers to is the importance of interculturalism in the integration and management policies of the diversity caused by immigration in Portugal and Spain in the early years of the $21^{\text {st }}$ century. Our principal goal is to know how interculturalism, in its polysemy, have got materiality in the practices and rules development of government agencies responsible for diversity management. We have also sort to investigate the perspectives of the other social actors, like associations representatives that have also been working with the subject of immigration. This article stems from a research that had been done on semi structured interviews, bibliography and documental research as well as direct observations. The data and arguments presented in this article maintains that; if isn't a definite solution for racism and xenophobia problems against immigrants, then interculturalism has advanced when compare with policies based on the assimilation idea

Keywords: Immigration Policies, interculturalism, immigration, Portugal, Spain. 


\section{El Lugar del Interculturalismo en Las Políticas Immigratórias en Portugal y España}

\section{Resumen:}

La cuestión central de este artículo consiste en reflexionar sobre el lugar del interculturalismo en las políticas de integración y gestión de la diversidad producida por los inmigrantes en Portugal y España en los primeros años del siglo XXI. Nuestro objetivo principal fue conocer como el interculturalismo, en su polisemia, ha logrado materialidad en avances y retrocesos de las normas y prácticas desarrolladas por órganos gubernamentales con el fin de gestionar la diversidad. Procuramos también conocer la perspectiva de otros actores sociales, como representantes de asociaciones relacionadas al tema de la inmigración. El estudio que dio origen al artículo ha sido desarrollado con base en pesquisa bibliográfica y documental, entrevistas cualitativas y observación directa. Los datos y los argumentos presentados en este artículo permiten inferir que, si no es la solución definitiva para los problemas del racismo y xenofobia contra inmigrantes, el interculturalismo ha sido un avance en lo que si refiere a las políticas de inmigración e integración del inmigrante cuando se compara, por ejemplo, a las políticas basadas en la idea de la asimilación.

Palabras-clave: Políticas inmigratorias, interculturalismo, inmigración, Portugal, España. 


\section{Introdução}

A questão central deste artigo refere-se ao lugar do interculturalismo ${ }^{1}$ nas políticas de integração e gestão da diversidade produzida pelos imigrantes em Portugal e na Espanha até 2014, quando estas políticas sofrem alterações significativas nos dois países. Procuramos aqui responder questões tais como: 0 que se entendia por interculturalismo? Como esse termo aparecia nas normas e ações oficiais dos Estados Ibéricos? Do mesmo modo, como o interculturalismo era compreendido por alguns dos atores sociais diretamente relacionados com a questão imigratória? E ainda, como esse tema dialoga com questões relacionadas ao racismo e discriminação contra os imigrantes? Assim, nosso objetivo é conhecer como o interculturalismo, em sua polissemia, ganhou materialidade em avanços e recuos de normas e práticas desenvolvidas não apenas por órgãos governamentais, mas também por associações que estavam direta ou indiretamente ligadas ao tema da imigração.

O tema do interculturalismo representou uma inovação das políticas de integração de imigrantes e de gestão da diversidade por se opor à ideia de assimilação cultural que caracterizou esta mesma problemática na passagem do século XIX para o XX e por se basear no princípio de que a presença de imigrantes e de minorias étnicas representa uma oportunidade de desenvolvimento da cultura do país de destino. 0 interculturalismo é parte de um modelo pluralista de gestão da diversidade e se distancia do multiculturalismo ao criticar a ausência de diálogo entre co-

1 Neste artigo utilizaremos os termos "interculturalismo" e "interculturalidade" como sinônimos. No entanto, há autores que se dedicaram à diferenciação entre uma e outra expressão. A esse respeito, entre outras obras, consultar Dietz, Gunther. La interculturalidad entre el 'empoderamiento' de minorias y la 'gestión' de la diversidad. Puntos de vista: inteculturalidad. Madri, n. 12, v. 3, 12/2007 e Romero, C. G. Pluralismo, interculturalismo e interculturalidad. Propuesta de clarificación y apuntes educativos. Educación y futuro: Revista de Investigación Aplicada y experiencias educativas. n. 8, 4/2003, pp. 9-26. 
munidades e sua visão individualista do processo de integração (Fernández-Suárez, 2016).

O interculturalismo esteve no centro do debate acadêmico, das políticas oficiais e de práticas políticas e culturais de Portugal e Espanha nos primeiros anos do século XXI, quando passa a sofrer um processo de refluxo, desaparecimento e silenciamento da temática, em especial no âmbito estatal, mas também acadêmico. Esse recuo teve início na Espanha, mas, até onde podemos verificar, pode estar em andamento também em Portugal.

A pesquisa que deu origem ao artigo foi desenvolvida com base em pesquisa bibliográfica e documental, entrevistas qualitativas com base em roteiro pré-estruturado e observação direta. Os documentos e as entrevistas foram coletados durante o período de um estágio pós-doutoral entre os anos de 2013 e 2014 em Portugal e Espanha. Concentramo-nos nos documentos oficiais de maior abrangência. No caso da Espanha, em razão de sua organização político-administrativa, que prevê autonomia para suas comunidades, consultamos também documentação específica da Comunidade de Madri, que possui governo autônomo e com competências em matéria de intervenção social e, por extensão, sobre a integração da população estrangeira. As entrevistas foram realizadas nas cidades de Lisboa e Madri.

Dividimos o artigo em quatro partes. Na primeira, procuramos situar o debate sobre integração de imigrantes. Na segunda parte, contextualizamos os fluxos migratórios em Portugal e Espanha de modo a demonstrar o crescimento do número de entradas, mas também o fato de, nos últimos anos, terem ser tornado de novo país de emigração (González Ferrer, 2013; Peixoto et al., 2016). Na terceira e na quarta parte, discutimos o tema do interculturalismo como chave para a integração do imigrante e para a gestão da diversidade por ele criada a partir de documentos oficiais e de entrevistas com atores sociais diretamente envolvidos com a questão. 


\section{Integração de imigrantes e interculturalidade}

O tema da integração de imigrantes à sociedade receptora é indissociável do fenômeno da imigração dos últimos anos. 0 imigrante tem sido visto, representado, nomeado e normatizado, sobretudo, como trabalhador ou agente econômico (Sayad, 2000; Sassen, 2013). A história, no entanto, tem cumprido com o papel de demonstrar que, como tal, o significado do imigrante e da imigração é reduzido a apenas uma de suas múltiplas facetas ou a um de seus significados. Isso porque o imigrante e a imigração são, também, um fenômeno identitário, isto é, um fenômeno identitário que questiona e redefine os processos sociais de construção do pertencimento e da alteridade (Ennes e Marcon, 2014).

Como expressão da questão identitária, as migrações provocam modificações nas configurações sociais nos países receptores. Isso significa que o imigrante altera as relações sociais ao constituir novos grupos e/ou integrar outros já existentes. A presença do imigrante, ainda que algumas vezes estimulada pelo próprio país receptor, produz, quase que invariavelmente, o seu estranhamento por parte dos nacionais (Bauman, 1999a, Simmel, 2005, Ramos, 2010, 2014). Além de entrar em disputa com nacionais, o imigrante, seu idioma, seu sotaque, sua religião, sua gastronomia, seus traços fenótipos e suas roupas típicas, como expressões da alteridade, perturbam e ameaçam os mecanismos simbólicos e materiais das relações de pertencimento existentes no local de destino. Assim, o imigrante e a imigração têm sido vistos como um elemento desestabilizador da coesão social e dos Estados nacionais (Ennes, 2016).

Do ponto de vista da gestão da diversidade, o interculturalismo procurou criar políticas e ações, muitas delas no campo da educação, mas também de modo transversal em vários outros setores da administração pública, de modo a desenvolver uma nova visão e uma nova prática cultural cuja ênfase não está apenas 
no convívio distante com o diferente, mas no intercâmbio e na aprendizagem recíproca (Ennes, 2014).

\section{M igrações em Portugal e Espanha contemporâneos}

No final de 2013 e início 2014, a imprensa internacional noticiou casos extremos de violência contra o imigrante. Apenas para ficar entre alguns dos casos mais noticiados, lembramos aqui do naufrágio que matou cerca 360 pessoas próximo à Ilha italiana de Lampedusa, no Mar Mediterrâneo, no ano de 2013. Da expulsão de uma estudante romena e de sua família nesse mesmo ano na França e no início de 2014 a morte de 15 pessoas em razão da ação da Guarda Civil Espanhola, que atirou balas de borracha contra um que tentava chegar a nado na cidade de Ceuta.

Segundo a ONU, em 2013 havia mais de 231 milhões de imigrantes em todo o mundo (ONU, 2013). 0 mesmo relatório da ONU indica o crescimento generalizado dos fluxos imigratórios. Portugal e Espanha encontram-se dentre os principais destinos europeus de imigrantes, o que tem feito crescer o número de imigrantes em relação à população nativa. Observar-se que em Portugal essa proporção manteve-se abaixo, no entanto, próxima à observada em toda a Europa. A Espanha, por sua vez, no ano 2010 (ONU, 2013) conheceu um aumento significativo de mais de $275 \%$ do número de imigrantes, alterando significativamente sua relação com a população nativa.

O crescimento da imigração está associado a um período de crescimento econômico na Europa. No caso de Portugal, que pode ser tomado como uma tendência para todo o continente, a imigração esteve associada à demanda de mão de obra para o setor da construção civil para homens, e limpeza e serviços domésticos para as mulheres (Dias e Dias, 2012). No que diz respeito à nacionalidade dos principais grupos de imigrantes, em Portugal, destacam-se os brasileiros, que sozinhos representam 
quase $1 / 4$ de todos os imigrantes. Depois dos brasileiros, as nacionalidades mais frequentes eram a ucraniana (11\%) e cabo-verdiana (10\%) (Dias, 2013). Na Espanha, os maiores grupos de imigrantes, formados por romenos, marroquinos e equatorianos, representam, respectivamente, $17 \%, 16 \%$ e $7 \%$ de todos os imigrantes no país ${ }^{2}$.

A crise econômica iniciada em 2008 colocou fim ao período de prosperidade no qual a Europa viu crescer os fluxos imigratórios. Sob a crise, a questão da diversidade e as políticas de gestão da integração dos imigrantes ganham novos contornos. A crise econômica tem produzido, além de altas taxas de desemprego e recessão econômica, cortes de recursos públicos e de investimentos na assistência social, em especial, na educação e saúde. Esses são dados importantes que compõem o contexto no qual as políticas de integração e o debate sobre interculturalismo têm ocorrido nos últimos anos.

\section{Imigração, gestão e interculturalidade: documentos}

A problemática da integração é uma constante entre as preocupações dos Estados nacionais. Em razão disso, vêm desenvolvendo políticas que estiveram e estão atreladas à percepção e compreensão do significado da diversidade cultural produzida pela presença do imigrante. Da perspectiva intercultural, a diversidade deixou de ser considerada apenas como uma ameaça e, por isto, ao invés de apagada ou eliminada, a exemplo das políticas assimilacionistas do final do século XIX e início do século XX, passou a ser tema e conteúdo de políticas de gestão.

O tema do interculturalismo ganhou espaço significativo das políticas de gestão da diversidade nas últimas décadas. Nesse

2 Fonte: Extranjeros residentes en España. Ministerio de Empleo y Seguridad Social. Setembro/2013. 
âmbito, o tema da interculturalidade ganhou vários usos e conotações que vão desde seu entendimento como um novo paradigma (Ramos, 2008) até a sua crítica como expressão da normatização e da consequente despolitização (Dietz, 2007), passando pelos desafios de equacionar as ambivalências e contradições produzidas pelas desigualdades sociais e diferenças étnicas e culturais (Romero, 2003; Peixoto, 2013).

Do ponto de vista institucional, a questão migratória em Portugal está sob a responsabilidade de um Alto Comissariado. 0 nome e as funções desse órgão vêm passando por mudanças desde sua criação. Quando surgiu, em 2002, era denominado Alto Comissariado para a Imigração e Minorias Étnicas - ACIME (Portugal, 2002), em 2007. Após sua unificação com outros órgãos voltados para questões migratórias e de minorias étnicas, passou a ser chamado de Alto Comissariado para as Imigrações e Diálogo Intercultural - ACIDI (Portugal, 2007). Em 2014, ganhou a denominação atual, Alto Comissariado para as Migrações ${ }^{3}$ - ACM (Portugal, 2014).

Em todas suas versões, o órgão máximo do Estado português voltado a questões migratórias responde diretamente ao Conselho de Ministros. Isso quer dizer que, se de um lado não está submetido a um ministério em específico, como é o caso da Espanha, que, como veremos, está vinculado ao Ministério do Trabalho; esse órgão possui uma inserção que pode ser considerada transversal em todo o aparato político-administrativo do Estado português. Até o início de $2014^{4}$, o órgão era constituído por uma rede formada pelos Centros Nacionais de Apoio ao Imigrante (CNAI) e os Centros Locais de Integração de Imigrantes (CLAII). Essa rede procurava dar amparo normativo ao criar po-

30 Alto Comissariado para a Imigração e Diálogo Intercultural resultou da fusão do Alto Comissariado para a Imigração e Minorias Étnicas, da estrutura de apoio técnico à coordenação do Programa Escolhas, da Estrutura de Missão para o Diálogo com as Religiões e do Secretariado Entreculturas (Portugal, 2007).

4 Quando encerramos a coleta de dados da pesquisa que deu origem a este artigo. 
líticas públicas e implementar ações de integração do imigrante (Peixoto, 2013, p. 164).

Para evidenciar a importância do interculturalismo para as políticas portuguesas de integração do imigrante pontuaremos alguns aspectos do II Plano de Integração do Imigrante (PII 2010 $2013)^{5}$. 0 documento foi desenvolvido com o apoio e fomento da Presidência do Conselho de Ministros, Alto Comissariado para a Integração e Diálogo Intercultural (ACIDI) e do Fundo Europeu para Integração de Nacionais de Países Terceiros (FEINT). O PII 2010 - 2013 anuncia a promoção da diversidade e da interculturalidade e o cuidado com os idosos imigrantes como duas novas áreas de intervenção. 0 documento está dividido em 17 áreas de intervenção ${ }^{6}$, dentre elas há as áreas de diversidade e interculturalidade. Essas 17 áreas de intervenção foram, por sua vez, divididas em 90 medidas.

A análise do documento permite verificar que um pouco menos de um terço de todas as áreas do Plano possui ações que fazem menção direta ao interculturalismo. Dessas, a área 15, "Promoção da diversidade e da interculturalidade”, possui, proporcionalmente, o maior número de medidas que fazem explicitamente referência ao interculturalismo. A ênfase é dada à promoção da diversidade cultural e religiosa, seja por meio da mídia e da opinião pública, seja em nível local. Há, também, medidas voltadas aos servidores públicos e mediadores culturais. Tanto no caso dos servidores públicos quanto dos mediadores, a área prevê a criação de um "referencial intercultural". A medida 81 prevê a realização de um diagnóstico sobre a "inserção de agentes de

5 Esse documento sucedeu o Plano Elaborado para o período anterior (2007 - 2009). 6 Acolhimento; Cultura e língua; Emprego, Formação profissional e dinâmicas empresariais; Educação; Solidariedade e segurança social; Saúde; Habitação; Justiça; Racismo e discriminação; Acesso à cidadania e participação cívica; Associativismo imigrante; Descendentes de imigrantes; Idosos imigrantes; Relações com os países de origem; Promoção da diversidade e da interculturalidade; Questões de gênero; Tráfico de seres humanos. 
mediação intercultural em serviços públicos". As áreas 2, cultura e língua; 4, educação; 9, racismo e discriminação; e 11, Associativismo imigrante possuem, cada uma, cerca de um terço de medidas que faz referência à interculturalidade. Nessa área, há duas medidas, uma voltada aos vários domínios e atividades da cultura e da língua e, outra, destinada à sensibilização dos produtores culturais. A área 4 (educação), por sua vez, apresenta três medidas interculturais. A primeira refere-se à formação intercultural de professores, a segunda prevê a inserção de agentes de mediação intercultural em contextos escolares e, terceiro, a divulgação de recursos pedagógicos interculturais nas escolas. $\mathrm{Na}$ área 9 (racismo e discriminação) há uma medida declaradamente intercultural que prevê combate à discriminação racial nos esportes. Já na área do Associativismo imigrante existe uma medida destinada ao apoio de projetos com vistas à integração de imigrantes.

Outras áreas destinam um percentual ainda menor de medidas à promoção da interculturalidade. A área 12 (Descendentes de imigrantes) destina uma medida, o que representa $25 \%$ de todas as medidas desta área, que orienta uma maior sensibilização da mídia para o tema da imigração. 0 percentual de medidas interculturais cai para $1 / 5$ na área de saúde (número 6), que prevê a formação intercultural de agentes do serviço nacional de saúde.

Com base no documento em análise, pode-se inferir que a ênfase das medidas interculturais no PII recaiu sobre a formação, seja no âmbito escolar, seja no profissional, sobre a sensibilização da sociedade e, por fim, pela inserção e atuação da figura dos agentes mediadores interculturais que passam a desempenhar o protagonismo destas medidas no novo período de ação do documento.

A Comunidade de Madri mantém órgãos públicos relacionados à imigração ligados ao Conselho de Imigração e Cooperação. Os nomes desses centros são, sugestivamente, "hifenizados" de 
modo a ligar as referências à Espanha e ao país de Origem. Assim, a Comunidade de Madri mantém uma série de órgãos denominados Centros de Participação e Integração da Comunidade de Madri (CEPI), a exemplo do Centro Hispano-Paraguaio, do Centro Cultural Hispano-Colombiano, do Centro Cultural Hispano-Equatoriano, dentre outros. Esses centros, ainda que tenham uma direção nomeada pela Comunidade, são geridos por associações e entidades sem fins lucrativos, algumas delas de imigrantes.

A gestão da integração do imigrante percorre na Espanha um caminho institucional distinto do observado em Portugal. Isso em razão da organização político-administrativa do país, que a despeito de prever a responsabilidade do Estado espanhol sobre a gestão da imigração, convive com as atribuições das comunidades autônomas em relação às demandas sociais, entre elas saúde, educação, assistência social e cultural (Fernández-Suárez, 2015, pp. 6-7). Essa particularidade instaura não apenas políticas e ações complementares, mas também conflitos e disputas relacionados ao processo de integração dos imigrantes, entre os vários níveis administrativos.

Por outro lado, assim como Portugal, a Espanha tem desenvolvido documentos oficiais com vistas ao processo de integração de imigrantes e gestão da diversidade. Tal como Portugal, esses documentos têm sido elaborados desde uma perspectiva intercultural da diversidade. O II Plano Estratégico: Cidadania e Integração (PECI) (2011 - 2014) ${ }^{7}$ (España, s/d) elaborado pelo Ministério do Trabalho e Imigração foi objeto de acordo no Conselho de Ministros. No campo das políticas de integração, percebe-se a influência ou relação entre investigadores e políticos, especialmente na Espanha (Garcés Mascareñas e Sánchez Montijano, 2015, pp. 185-186), como é o caso do II PECI que foi dirigido pelo especialista Carlos Giménez. 0 documento reúne 
uma longa análise dos resultados do primeiro plano, bem como a evolução da legislação e do aparato normativo no âmbito da União Europeia. O II PECI define como seus ideais os valores característicos da sociedade democrática e do Estado Social de Direito e estabelece como seus princípios "[...] a igualdade, a cidadania, a inclusão e a interculturalidade” (Espanha, S/D, p. 93).

O II PECI se assenta em quatro princípios: igualdade, cidadania, inclusão e interculturalidade. A interculturalidade, a exemplo do plano português, tem caráter transversal e é mencionada literalmente na grande maioria de suas áreas de atuação. 0 documento que apresenta o Plano espanhol é mais extenso do que o português. De modo alternativo, foi divulgada uma versão resumida (Madri, 2011) na qual dá ênfase ao conteúdo do plano propriamente dito. Seja na versão completa, seja na versão resumida, o II PECI está dividido entre as áreas gerais e as transversais. As áreas gerais são: acolhida, empregos e promoção econômica, educação, saúde, serviços sociais e inclusão, mobilidade e desenvolvimento. Já entre as transversais estão convivência, igualdade de tratamento e luta contra a descriminação, infância, juventude e famílias; gênero e participação e educação cívica.

Ao contrário do documento português, o II PECI não possui nenhuma área específica voltada ao interculturalismo, ainda que figure como um dos quatro princípios do Plano. Além disso, mais de dois terços de todas as áreas do Plano incluem ações interculturais. Dentre as gerais, é a área 1, Acolhimento, em que encontramos o maior número de referências à interculturalidade, o que representa praticamente um quarto de suas medidas. Na área de educação há $10 \%$ de medidas com referência direta ao interculturalismo, e nas áreas de saúde e serviço, esta referência fica próxima aos 8\%. No conjunto das seis áreas gerais, apenas duas não possuem medidas que fazem menção ao interculturalismo.

Dentre as medidas das cinco áreas transversais do II PECI (a saber: convivência; igualdade de tratamento e luta contra a dis- 
criminação; infância, juventude e famílias; gênero e participação e educação cívica), a interculturalidade só não aparece na área do gênero. Nas demais áreas, observa-se uma maior referência na área de convivência, com quase $20 \%$, e nas demais áreas, a proporção de medidas que citam literalmente a palavra interculturalismo fica abaixo de $5 \%$.

No conjunto de todas as áreas, sejam elas gerais, sejam transversais, o interculturalismo é citado literalmente em cerca de 10\% das medidas. Quando analisado apenas do ponto de vista quantitativo, o lugar e a importância do interculturalismo no II PECI parecem pequenos e até mesmo secundários. No entanto, a leitura de todo o documento nos permite perceber que como princípio, e como ênfase, o tema do interculturalismo possui uma importância considerável, mesmo quando analisamos apenas a parte das áreas de atuação do documento. Isso porque o tema aparece de modo recorrente nos textos introdutórios, diagnósticos e objetivos de cada área do documento. Portanto, ainda que do ponto de vista das medidas, ou seja, na parte operacionalizável do plano, a quantidade de medidas seja pequena, a ideia do interculturalismo norteia o conjunto do II PECI.

No que diz respeito às medidas interculturais, as ações mais recorrentes são as ligadas à educação. Ações como formação, fomento, capacitação, atualização, desenvolvimento, material didático e redes, como as áreas acima discriminadas já nos permitem antever, não se restringem ao ambiente e aos profissionais de escolas e procuram envolver outros setores e profissionais da administração pública, em especial os que de alguma forma convivem com imigrantes e seus filhos.

Como já foi dito, a organização política e administrativa da Espanha se caracteriza pela autonomia de suas comunidades. Em Madri, foram encontrados três documentos relativamente recentes sobre o tema. Trata-se do Primeiro e Segundo Planos Madri de Convivência Social e Intercultural desenvolvidos, res- 
pectivamente, para os períodos de 2005 a 2008 e 2009 a 2012 . 0 Manual de Integração na Cidade de Madri, o terceiro documento, datado de 2014, portanto, em vigência no período estudado, por outro lado, não faz nenhuma referência ao tema da interculturalidade. Além disso, o documento, ao contrário dos anteriores, consiste basicamente em um catálogo por meio do qual o imigrante legalizado, ou que busca a legalização, pode encontrar os órgãos públicos voltados ao emprego, trabalho, educação, saúde, habitação, dentre outros, saber quais os documentos necessários e como proceder.

O recuo em relação ao interculturalismo sinalizado no último documento madrileno reaparecerá em uma das entrevistas realizadas com representantes de associações de imigrantes na capital espanhola. De uma perspectiva mais ampla, os recuos observados nas políticas de imigração dos países ibéricos no que tange o tema do interculturalismo não devem deixar de ser pensados como parte da dinâmica de desestabilização (Bauman, 1999b, 2005; Castells, 1999; Appadurai, 2006) e de contra-desestabilização dos Estados nacionais. Essa importante problemática, no entanto, escapa aos objetivos e limites deste artigo.

\section{Políticas de gestão, preconceitos e interculturalismo: narrativas}

Vejamos agora como o interculturalismo institucionalizado sob a forma de normas e ações oficiais dialoga com as representações e iniciativas de atores sociais vinculados a entidades que mantinham relações diretas com imigrantes nos dois países estudados.

Na associação hispânico-paraguaia em Madri, fomos recebidos em um primeiro momento pela coordenadora da entidade. A coordenadora nos explicou o funcionamento dos centros e, entre uma explicação e outra, destacou que a primeira função dos centros é encontrar emprego para os imigrantes legalizados. Essa 
concepção sobre a figura do imigrante nos pareceu contrastar significativamente com a abordagem da Alta Comissária em Lisboa, cuja narrativa estava muito mais voltada às questões culturais do que econômicas. Na ocasião, a então Alta Comissária procurou demonstrar a especificidade do modelo de integração de imigrantes a partir da perspectiva da reciprocidade:

Eu acho que os grandes princípios básicos das nossas políticas são o acolhimento, a integração e criar mecanismos para que as pessoas se possam de fato integrar, mas é esta vertente do diálogo intercultural, trabalharmos com a sociedade no seu todo e não só com quem chega (Rosário, nov/2013).

Para a Alta Comissária, os princípios básicos de acolhimento e integração não se baseiam em uma relação unilateral, ou seja, na "absorção" do imigrante da cultura do país de destino. A orientação das políticas de integração portuguesas tinha em vista o conjunto da sociedade por meio do que denomina de vertente intercultural. Nessa direção, a Alta Comissária, ao mesmo tempo em que reconhece a existência de críticas, justifica as ações do ACIDI.

Dentre as associações entrevistadas em Portugal, as opiniões de seus representantes oscilam entre adesões - ora mais tácitas, ora mais declaradas - e uma oposição explicita formulada, como por meio da crítica à inconsistência das políticas imigratórias a partir de denúncias de violação de direitos humanos. 0 tom crítico da fala do presidente da Associação Solidariedade Imigrante em Lisboa tem como contraponto a maneira conciliatória dos representantes da Associação dos Antigos Guerrilheiros Angolanos em Portugal (AAGA).

De 1 a 10, para mim, é 8. Pena que agora há alguns cortes porque tinha que ser. Porque o país está a cortar, o governo deve fazer os seus ajustamentos. Mas quem já vive cá há 
muitos anos sabe que o sistema português foi muito bom (Domingos, jun/2014).

Domingos, ao mesmo tempo em que reconhece a eficácia de medidas oficiais de amparo às famílias imigrantes, também justifica as atuais mudanças nestas ações em razão da crise econômica e dos cortes necessários.

De uma perspectiva mais crítica, o presidente da Associação Solidariedade Imigrantes questiona as atividades promovidas pelo ACIDI:

[...] fazer um concerto com artistas famosos onde o povo não tem roupa para ir, não tem dinheiro para comprar o bilhete. Isso é uma interculturalidade entre estados e não do povo. Ou seja, os poderes, seja local, seja poder central..., não dão condições para a sociedade civil para ela promova essa vivência intercultural. Que a democracia representativa não peça tudo, e que deixe a democracia participativa órfã de tudo (Timóteo, fev/2014).

Timóteo refere-se à predominância dos mecanismos da democracia representativa e à cooptação do tema da interculturalismo pelas dinâmicas do consumo cultural. Por outro lado, reconhece a existência do interculturalismo para além das políticas oficiais: "Agora se estivermos falando em vivência intercultural entre bairros excluídos, é claro que ela existe. Há bairros heterogêneos incríveis, onde vivem pessoas de vários lugares do mundo".

Em Madri, na entrevista com Nina ${ }^{8}$, não foi abordado diretamente o tema das políticas de integração de imigrantes na Espanha. A questão, no entanto, aparece indiretamente a partir de dois aspectos mencionados na entrevista. 0 primeiro se refere às re-

8 Nina é uma das lideranças de uma associação que em Madri comercializa objetos de arte e artesanato de vários países africanos e na África atua em missões humanitárias. 
presentações oficiais sobre as influências e relações culturais com a América Latina. 0 segundo está ligado aos cânones oficiais da cultura espanhola. A partir da crítica às políticas desenvolvidas por órgãos oficiais madrilenos ligados à cultura. “¿Qué posibilidad de transmisión tenemos de estas instituciones, se también desconocen e ignoran? Se siguen el pre-colombino, aquí la cultura es Cervantes, Quijote y el jumenco y todo el año insiste". Em contraposição, Nina questiona sobre o desconhecimento e distanciamento que a Espanha mantém em relação ao continente africano. "La España tiene mucho una relación cultural con América Latina, pero con África, que está 14 kilómetros abajo, eso absolutamente no existe" (Nina, dez/2013). Isso tem um correlato na percepção da opinião pública e das políticas de imigração mais favoráveis a aceitar imigrantes procedentes da América Latina e rejeitar com maior ênfase as migrações procedentes do norte da África e dos países Subsaarianos.

De uma maneira geral, considerando as entrevistas utilizadas neste artigo, reconhece-se a existência do preconceito e do racismo tanto em Portugal como na Espanha. Há, no entanto, diferentes interpretações para o fenômeno. A representante do ACIDI entende que, em Portugal, de "uma maneira geral, a opinião pública é uma opinião pública amiga da diversidade". A Alta Comissária se refere à discriminação e ao racismo em Portugal como um problema de difícil combate em razão de se expressar muitas vezes de maneira invisível e intangível para as leis antidiscriminatórias existentes no país como, por exemplo, na discriminação em situações de locação de imóveis ou emprego. Esse cenário otimista em relação ao racismo no país pode ser reforçado pelo fato do Partido Nacional Renovador (PNR), único partido português que possui um claro posicionamento xenófobo, ter uma pequena e quase insignificante representação eleitoral (Kumar, 2012).

Os representantes da Associação dos Guerrilheiros opinam de modo tão cauteloso quanto a representante do Estado português. 
Não há dúvidas quanto à questão xenofóbica também existe. Existe e é um fato incontrolável, mas a convivência, a forma assídua dos universitários, as universidades também permitem que essa desigualdade acabe ${ }^{9}$ (Domingos, jun/2015).

Para Domingos, o problema do preconceito e do racismo em Portugal tem sido amenizado pelo fluxo permanente com Angola em razão de migrações de retorno em definitivo ou provisoriamente, o que ajudaria a "preparar" o futuro imigrante. Isso porque o retornado transmitiria informações sobre os costumes e as leis do país de destino. Além disso, a incorporação dos filhos de imigrantes no mercado de trabalho, no funcionalismo público, inclusive na polícia, funcionaria como forças amenizadoras do preconceito e da discriminação. 0 tempo, portanto, funcionaria tanto no país de origem quanto no país de acolhida a favor da integração.

Na Espanha, os casos de discriminação são mais fortemente destacados entre os entrevistados. Para Pilar ${ }^{10}$, o preconceito contra imigrantes é diferenciado. Os latino-americanos, segundo a entrevistada, são os que menos reclamam de sofrer discriminação em Madri. Já os marroquinos seriam vítimas de preconceito por motivos religiosos. Haveria, também, formas mais indiretas e sutis de discriminação contra imigrantes. Nesse caso, em especial, contra os africanos. Essa discriminação não está apenas associada às características étnico-raciais e aos traços fenótipos, mas também a barreiras culturais enfrentadas para se ter acesso a recursos financeiros públicos voltados à constituição e manutenção de associações de imigrantes.

Ainda para Pilar, os imigrantes têm sido utilizados como bode expiatório para a crise econômica na qual Espanha está mergulhada. Segundo a entrevistada, os políticos, aproveitando-se do várias denúncias de atos racistas de estudantes portugueses contra estudantes estrangeiros. 10 Pilar é espanhola, trabalha como psicóloga para uma associação de imigrantes paraguaios que mantém um dos Centros Culturais da Comunidade de Madri. 
fato da maioria dos imigrantes não votar e, portanto, sem correr o risco de perderem votos, associam os imigrantes à crise, em particular ao desemprego. Assim, fazem desse tema um dos principais pontos da agenda política nas últimas eleições. Desse modo, a opinião pública estaria associando os imigrantes à crise econômica: "Si, esta faltando trabajo, es mejor que esa gente se vaya!!”. Ao mesmo tempo, o vínculo entre imigração e crise coloca em questão a aplicação de recursos públicos em projetos, órgãos, empregos associados à imigração e ao imigrante, a exemplo do fechamento de alguns dos centros culturais do município de Madri destinados à gestão da imigração.

De acordo com Vladimir ${ }^{11}$, da Associação Rumiñahui, existe discriminação contra o imigrante na Espanha, em particular em Madri, não obstante o aparato normativo até então existente e os esforços de pesquisadores no desenvolvimento de políticas e ações interculturais. Na opinião do entrevistado a discriminação, o preconceito e a xenofobia estão presentes no cotidiano seja de forma mais velada, seja forma mais explícita. Para o entrevistado, por exemplo, a identificação do imigrante por meio de seus traços fenótipos e do estigma por ele produzido é um obstáculo no aluguel de moradias bem como são acionados como marcadores associados à criminosos. Além disso, a discriminação se expressa na concentração de imigrantes em determinadas escolas pouco valorizadas e evitadas por espanhóis. Na percepção do presidente da Associação Hispano-Equatoriana, a discriminação contra imigrantes tem se revelado, assim, de diversas formas. Na entrevista, Vladimir lembra de um raciocínio racista que julga ser comum entre os espanhóis em Madri. "Porque, mira yo no soy racista, pero quiero que vivan lejos de mí, pero quiero que no me topen en mi trabajo, pero quiero que vayan a educarse en otros colegios" (nov/2013).

As narrativas coletadas durante a pesquisa revelam uma realidade relativamente distinta em Portugal e Espanha no que diz

11 Equatoriano e presidente da Associação. 
respeito a importância do interculturalismo. Como vimos, do ponto de vista normativa, ambos países, ao menos até o início da década de 2010, haviam desenvolvidos políticas de integração do imigrante com base em uma perspectiva intercultural. A diferença mais acentuada parece estar no olhar e nas narrativas dos entrevistados. Em Portugal, estas narrativas apontam para uma perspectiva mais consensual. De um lado, a representante do, então, ACIDI, ressalta os avanços da política de integração portuguesa, o que encontra ressonância em uma das entrevistas com representantes de associações de imigrantes. No entanto, a opinião do presidente da Associação Solidariedade Imigrante nos afasta de um possível consenso sobre o tema em Portugal. Esta perspectiva em que se reconhece os limites e as tensões entre as políticas interculturais e a vivência cotidiana pelos imigrantes no país pôde ser observada durante nosso trabalho de campo em Lisboa quando tivemos a oportunidade de participar de dois eventos culturais. Um na Linha de Sintra e outro na região da Mouraria ${ }^{12} e$, assim, como Vladimir havia destacado em relação ao caso espanhol, a presença de portugueses nessas ocasiões era bem inferior ao da participação de estrangeiros ${ }^{13}$.

Já na Espanha, se há alguma perspectiva mais consensual ela está orientada por crítica em relação às distâncias entre os resultados das políticas interculturais de integração (que como visto já sofriam um forte refluxo no momento da pesquisa) e a vivencia prática no cotidiano espanhol. As entrevistas realizadas com imigrantes e representantes de associações em Madri,

12 A Linha de Sintra é uma região periférica de Lisboa onde há uma grande concentração de imigrantes. 0 evento foi uma espécie de "showmício" promovido por uma associação da localidade para promover a candidatura de um dos candidatos às eleições para as Câmaras Municipais em 2013. Já o Festival Imigrarte ocorreu em um prédio destinado a atividades artísticas e culturais na região Martim Moniz, área central de Lisboa. Esse Evento foi promovido pela Associação Solidariedade Imigrante e consistiu basicamente em espetáculo de música, danças, comidas típicas e oficinas artísticas. Havia ainda, a presença de algumas organizações de combate a violência contra mulheres e contra racismo.

13 Sobre o Festival Emigrarte ver Ennes e Ramos (2018). 
revelaram uma maior tensão, quando não maior distância entre o que foi proposto em termos de políticas e ações interculturais por parte da Comunidade e a vivência neste mesmo contexto.

\section{Apontamentos finais}

O principal objetivo deste artigo foi refletir como o tema do interculturalismo aparece na problemática imigratória em Portugal e Espanha baseando-se em pesquisa bibliográfica e documental, além da coleta de entrevistas e observação direta. 0 artigo dá conta do aumento e complexização do fenômeno migratório no mundo contemporâneo, em especial nos países estudados, isto é, não apenas cresceu o número de pessoas que vivem fora de seu país de origem, mas também sua presença nos países de destino enseja uma multiplicidade de questões que vão muito além do entendimento das migrações no âmbito das atividades econômicas.

Portugal e Espanha, nas últimas décadas, passaram a figurar entre os países europeus com o maior número de imigrantes. Nesses dois países, o interculturalismo passou a compor o cerne dos planos de integração e gestão da imigração. Em razão de suas especificidades políticas e administrativas, no entanto, a operacionalização das ações e medidas previstas nos planos governamentais tiveram suas diferenças. Em Portugal, a imigração esteve sob a responsabilidade de um órgão, cuja nomenclatura vem passando por modificações, diretamente ligado ao Conselho de Ministros, o que lhe garante, além de uma inserção transversal, diretrizes mais unificadas para o conjunto do Estado e território português. No caso da Espanha, em razão da significativa autonomia de suas Comunidades, as políticas imigratórias tendem a possuir matizes relativamente variadas.

A análise do II Plano de Integração do Imigrante (2010 - 2013) em Portugal e do II Plano Estratégico: Cidadania e Integração 
(2011 - 2014) na Espanha permitiu verificar a importância do interculturalismo como chave para as políticas de integração e gestão do imigrante e da imigração, pelo menos no discurso ou narrativa dos documentos aqui analisados. Ainda que em Portugal a transversalidade dessas políticas tenha uma existência institucional na figura do ACIDI, órgão diretamente ligado ao Conselho de Ministros, o documento espanhol também demonstrou a preocupação com o tema em várias áreas do governo. Observou-se, assim, tanto no caso português como no espanhol, uma ênfase em medidas de formação de profissionais que atuavam não apenas na educação, mas também em outras áreas do governo, como saúde. No entanto, a importância que o interculturalismo ocupava nas políticas oficiais passou a sofrer um recuo, o que ficou evidente no Manual de Integração na Cidade de Madri de 2014, que não faz nenhuma menção ao tema. Em Portugal ocorreu no início desse mesmo ano a mudança do nome e das atribuições do antigo ACIDI, que passou a se chamar ACM (Portugal, 2014). Essas mudanças estão diretamente ligadas à crise econômica que atinge Portugal e Espanha, além da chegada de governos conservadores no poder, na Espanha como um todo e em Madri em específico. Em Portugal foi possível verificar que o desaparecimento da referência ao interculturalismo no nome do Alto Comissariado está relacionado, dentre outros fatores, à necessidade do órgão de se ocupar do fenômeno da emigração de seus cidadãos que vem crescendo nos últimos anos.

Por meio das entrevistas, a questão da integração e do interculturalismo mostrou-se menos consensual. Em Portugal, as entrevistas, de certo modo, são ilustrativas de uma percepção de que a imigração, o imigrante e o interculturalismo suscitam uma situação menos tensa e conflitiva, não que isso signifique que não haja tensões, conflitos decorrentes de racismo e preconceito contra imigrantes.

Os dados e os argumentos apresentados neste artigo permitem verificar que, em Portugal e Espanha, as políticas interculturais 
são marcadas por avanços e recuos, o que tem colocado o debate sobre a integração do imigrante em um nível de maior complexidade e que, mesmo com suas ambivalências e contradições, tem contribuído para problematizar de modo mais objetivo e sistemático as várias formas e práticas de preconceitos contra o imigrante.

\section{Referências}

Appadurai, A. El rechazo de las minorias: Ensayo sobre la geografia de furia. 2. ed. Barcelona: Tusquet Editores, 2006.

Bauman, Z. Modernidade e ambivalência. Rio de Janeiro: Zahar, 1999a.

. Globalização: as conseqüências humanas. Rio de Janeiro: Jorge Zahar, 1999b.

Identidade: entrevista a Benedetto Vecchi. Rio de Janeiro: Jorge Zahar Editor, 2005.

Castells, M. 0 Poder da Identidade. 2. ed. Rio de Janeiro: Paz e Terra, 1999.

Dias, B. P., Dias, N. (org.). Imigração e racismo em Portugal: o lugar do outro. Lisboa: Edições 70/Le Monde Diplomatique, 2012, pp. 29-45

Dias, P. et al. Relatório de imigração, fronteiras e asilo - 2012. Oeiras, Portutal: Serviço de Estrangeiros e Fronteiras, 2013.

Dietz, G. La interculturalidad entre el 'empoderamiento' de minorias y la'gestión' de ladiversidad. Puntos de vista: inteculturalidad. Madri, n. 12, v. $3,12 / 2007$.

Ennes, M.A. Aprender com o imigrante: A produção multi/intercultural da diversidade em Portugal. Cadernos CERU/USP, v. 25, n.1, 2014, pp. 197-224.

Ennes, M. A. e Marcon, F. N. Das identidades aos processos identitários: repensando conexões entre cultura e poder. Sociologias (UFRGS. Impresso), v. 16, 2014, pp. 12-34.

Ennes, M.A. A produção da diversidade: identidade e imigração. Revista Brasileira de Sociologia. n. 8, v. 4, dez/2016, pp. 217-242.

Ennes, M.A. e Ramos, N. A. presença brasileira em Portugal: interculturalismo e consumo cultural. In: Bógus, L. e Baeninger, R. A nova face da emigração internacional no Brasil. São Paulo: Educ, 2018. 
España. Ministério del Trabajo e inmigración. Plan Estratégico: cidadanía e integración. Resumen Ejecutivo. Madri: Dirección General de Integración de los Inmigrantes, [s/d].

Fernández-Suárez, B. Las políticas de integración de inmigrantes en España: ¿rumbo al asimilacionismo?. In Lanero Táboas, D.; Magalhães, P. T. (Coord.) Cadernos Mateus Doc, no. 9. Migración-Migration-Migração: Instituto Internacional Casa Mateus, 2016, pp. 61-81.

Fernández-Suaréz, B. El discurso político de integración de los inmigrantes en el nivel regional en España: la división entre políticas de identidad y políticas sociales. Tomo. São Cristóvão, SE, n. 26, jan/jun. 2015. p. 37 - 65.

Garcés Mascareñas, B.; Sánchez-Montijano, E. El papel de la investigación en las políticas de inmigración e integración. Estudio exploratório del policy-research nexus en España. Revista Española de Investigaciones Sociológicas, 152, 2015, pp. 179-188.

González Ferrer, A. La nueva emigración española. Lo que sabemos y lo que no. Zoom Político ํo8. Madri: Fundación Alternativas, 2013.

Madri. Plan estratégico ciudadanía e integracción: Resumen ejecutivo. Madri: Dirección General de Integracción de losinmigrante, 2011.

ONU. Trends in International Migrant Stock: The 2013 revision (United Nationsdatabase, POP/DB/MIG/Stock/Rev.2013). Disponível em: < http://esa. un.org/unmigration/migrantstocks2013.htm?mtotals

Peixoto, J. Imigração e cidadania. In: Lobo, Marina Costa (coord.) Portugal e a Europa: novas cidadanias. 1. ed. Lisboa: Fund. Francisco Manuel dos Santos, 2013, p. 164).

Peixoto, J. Tiago De Oliveira, Isabel; Azevedo, Joana; Marques, José Carlos; Góis, Pedro; Malheiros, Jorge; Madeira, Paulo Miguel. Regresso ao Futuro-A Nova Emigração e a Sociedade Portuguesa. Lisboa: Gradiva, 2016.

Portugal. Presidência do Conselho de Ministros. Decreto Lei 251/2002. Cria, na dependência da Presidência do Conselho de Ministros, o Alto Comissariado para a Imigração e Minorias Étnicas e revoga o Decreto-Lei n.o 3-A/96, de 26 de janeiro, e o Decreto-Lei n.․ 39/98, de 27 de fevereiro. 2002.

Portugal. Presidência do Conselho de Ministros. Decreto Lei 167/2007. Aprova a orgânica do Alto Comissariado para a Imigração e Diálogo Intercultural, I. P (ACIDI, I.P.), definindo as suas atribuições, órgãos e competências, 2007.

Portugal. Presidência do Conselho de Ministros. Decreto Lei 31/2014. Prova a orgânica do Alto Comissariado para as Migrações, I.P. (ACM, I.P.) que prossegue atribuições da Presidência do Conselho de Ministros (PCM) nas áreas da 
integração e migrações, definindo as suas atribuições, órgãos e competências, 2014.

Ramos, M. C. Impactos demográficos e sociais das migrações internacionais. In: Ramos, N. (org.). Saúde, migração e interculturalidade. João Pessoa: Editora Univesitária da UFPB, 2008, pp. 11-44.

Ramos, N. Interculturalidade e alteridade: dinâmicas contextos e políticas. In: Toutain, L. M.B., Serafim, J.F., Geffroy, Y. (org.). Perspectivas em informação visual: cultura, percepção e representação. Salvador: EDUFBA, 2010, pp. 4256.

Ramos, N. Conflitos interculturais no espaço europeu. In: Pina, Helena, Remoaldo, P., Ramos, M.C. (org.) Grandes problemáticas, do espaço europeu/ The overarching issues of the european space. Porto: Faculdade de Letras da Universidade do Porto, 2014, pp. 225-245.

Romero, C. G. Pluralismo, interculturalismo e interculturalidad. Propuesta de clarificación y apuntes educativos. Educación y futuro: Revista de Investigación Aplicada y experiencias educativas. n. 8, 4/2003, pp. 9-26.

Sassen, S. Inmigrantes y ciudadanos. De las migraciones masivas a la Europa fortaleza. Madri: Editorial Siglo XXI, 2013.

Sayad, A. La doble ausencia. De las ilusiones del emigrado a los padecimientos del inmigrado. Barcelona: Anthropos, 2000.

Simmel, G. 0 estrangeiro. RBSE. João Pessoa, PB. Vol. 4, n. 12. Dez./2005. pp 350-357.

Recebido em 28/02/2018

Aprovado em 15/03/2018 